\title{
EI Biodesarrollo como ruptura de la categoría desarrollo
}

The Bio-development as breaking development category ${ }^{1}$

\author{
Dustin Tahisin Gómez Rodríguez \\ Facultad de Ciencias Económicas \\ y Administrativas, Universidad de \\ San Buenaventura, Colombia. \\ E-mail:dgomez@usbbog.edu.co
}

Ehyder Mario Barbosa Pérez

Universidad de la Salle, Colombia.

E-mail: ebarbosap01@gmail.com

\author{
William Eduardo Rojas \\ Velásquez \\ Corporación Unificada de Educación \\ Superior CUN, Colombia \\ E-mail:william_rojasvel@cun.edu.co
}

Fecha de recepción: 13/03/2016

Fecha de aceptación: 21/11/2016

\section{Resumen}

El presente artículo de revisión tiene como objetivo realizar un breve análisis de la categoría desarrollo en las escuelas de la ciencia económica para identificar sus líneas argumentativas y así poder ampliar el debate de una revolución científica en términos de Kuhn de lo que es o puede ser el Biodesarrollo. El método utilizado es una revisión documental por medio de matrices. Para ello se realizó un estudio de las principales escuelas, se identifican sus categorías como sus conceptos, se identifica las caracte-

Palabras clave - biodesarrollo - economía - desarrollo - vida rísticas y aportes del Biodesarrollo, como propuesta que revitaliza la categoría desarrollo pero desde una perspectiva de promocionar la vida más que de la eficiencia y la eficacia orquestadas por el discurso hegemónico de la economía de mercado.

(1) El presente artículo de revisión es derivado del anteproyecto que adelanta la Universidad San Buenaventura sede Bogotá denominado «Bioeconomía y cambio climático» en colaboración del IGAC. En su fase de construcción se ha desarrollado como una electiva que oferta en el presente año el programa de Economía de la Universidad como con el semillero de investigación del mismo nombre. 


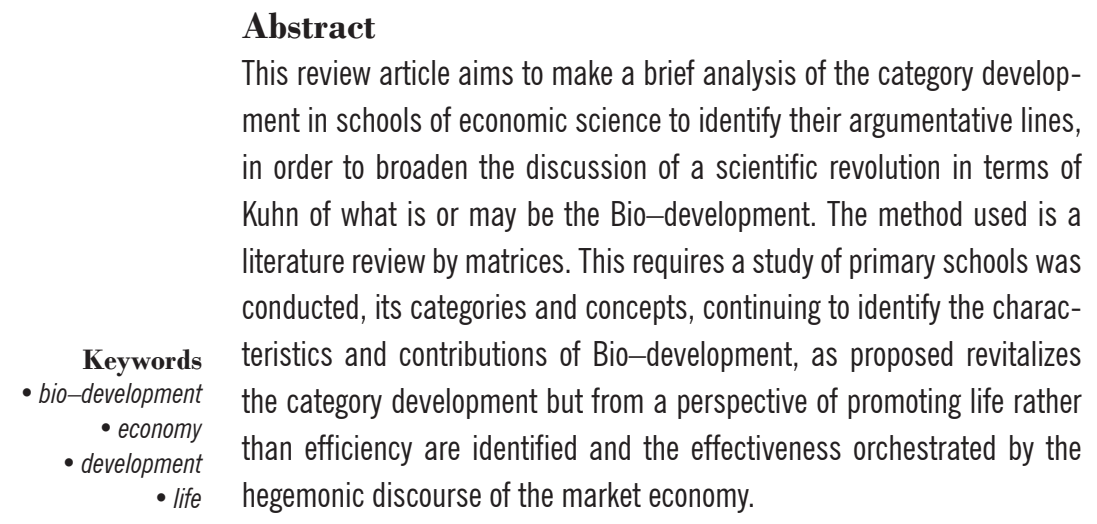

\section{Introducción}

El presente artículo de revisión tiene como objetivo realizar un breve análisis de la concepción de la categoría desarrollo en las escuelas de la ciencia económica para identificar sus líneas argumentativas y así poder ampliar el debate de una revolución científica en términos de Kuhn de lo que es 0 puede ser el Biodesarrollo. En efecto, la perspectiva del Biodesarrollo nace en primera instancia con los postulados del profesor Georgescu-Roegen quien en la década de 1960 postulaba que era necesario no aferrarse al paradigma dominante de la economía convencional, dado que sus hipótesis son reduccionistas. En virtud de que éstas habían dejado al hombre sin las características que lo hacen realmente humano (la incertidumbre, la información, el error, la desigualdad, lo irracional, entre otros), en contraposición lo han definirlo como un ser con comportamientos reproducibles en su relación con su entorno. Por ende, hay que sustituirlo por una perspectiva mucho más amplia en la cual se vea en términos de transformación entrópica (Carpintero, 2006; Goergescu-Roegen, 1996:20-366). En consecuencia, el Biodesarrollo es un enfoque del impulso para la vida, donde se abre hacia una la política de la multiplicidad y la diferencia. Es así que el pivote es la vida y ésta como un devenir de experimentación abierta, móvil, e incierta, que acrecienta y promueve la diferenciación como nuevas formar de existencia potencializando el ser (Gómez, Rincón e lbagon, 2015:142).

Un programa diseñado desde el Biodesarrollo habrá de reconocer que es necesario que constituyan sectores productivos que creen capacidades propias de los nuevos sujetos y agencias sociales, para integrarse creativamente al circuito de producción cognitiva, apropiándose, adaptándose y transformando nuevas tecnologías, para generar sistemas productivos alternativos, con formas originales de cooperación social del trabajo y de gestión de los recursos. (Useche, 2011:50)

Por lo tanto, las trasformaciones políticas y económicas desde la era industrial que ha realizado el hombre en aras del «progreso» como lo pregonaron los economistas clásicos, han generado en el presente todo lo contrario en la gran mayoría de los seres vivos que comparten en el planeta tierra, tanto en los animales humanos (Stiglitz, 2010) como no humanos (Muñoz, 2016:137), donde el empoderamiento del mercado en detrimento de otras relaciones humanas, como la cooperación y la irracionalidad, si no generan valor de cambio, han sido obliteradas por el discurso hegemónico (Hinkelammert, y Mora, 2008; Gómez et ál., 2015; Maturana y Pörksen, 2004; Maturana, 2002; De Soussa Santos, 2011). Por consiguiente, es imperativo que la ciencia económica amplíe las 
maneras como desglosa su objeto de estudio, con lo cual pueda promocionar otras miradas (Useche, 2012; 2011; 2008), como contribuir a reducir la inequidad, la contaminación apremiante como la pobreza generalizada de la población, así como entender las diferencias entre los tiempos de la productividad humana y los ciclos de la naturales (AEMA, 2015; BID, 2012; Andrade, 1994-1996; Gómez, 2013a, 2013b).

El método utilizado para realizar el artículo es del tipo de revisión documental. En un primer momento se analiza las tesis centrales tanto de los autores como de las teorías identificadas, para poder así generar relaciones entre ambos. En un segundo proceso se formaliza una sistematización como clasificación reflexiva de las líneas argumentativas de los autores donde se premia las simetrías y las asimetrías de los mismos para poder visualizar el problema de investigación del presente artículo (Salcedo Casallas, 2016). Con el mismo propósito para la recolección de la bibliografía utilizada se efectuaron matrices en las cuales el rastreo conceptual permitiera sistematizar los documentos derivados de bases de datos reconocidas a nivel nacional como internacional a través de Scopus, Science Direct. DOAJ, Ebsco Springer y Redalyc.

Por consiguiente, el presente documento realiza una introducción ya expuesta, luego, en un segundo momento, se realiza un breve análisis de las escuelas de la ciencias económica desde la categoría desarrollo, posteriormente se estudia las características y posibilidades del Biodesarrollo como propuesta, y finaliza con unas conclusiones que buscan fomentan el dialogo interdisciplinario como trasdisciplinario de la ciencia económica.

\section{Breve análisis de la categoría Desarrollo desde las escuelas o autores de la ciencia económica ${ }^{2}$}

\begin{tabular}{llll}
\hline Escuelas & Mercantilismo & Fisiócratas \\
preeconómicas ${ }^{3}$ & Para los mercantilistas su principal objetivo era & Los fisiócratas entendían el Desarrollo como la \\
& mantener una balanza de pagos positiva en la & realización eficaz y eficiente de la estructura \\
& cual hubiera una gran acumulación de oro. Para & agrícola de Francia, propiciando al mismo tiempo \\
& ellos, el Desarrollo era la aceleración del proceso & la competencia. Por ende, esta posición va en \\
& de crecimiento de la producción total. Es así que & contravía con los Mercantilistas que abogaban \\
& para llegar a este punto instituían que era necesario & por la industria manufacturera así como por el \\
& la utilización de los factores disponibles como el & intervencionismo del Estado. \\
& trabajo, la capacidad tecnológica y el aumento del & De igual manera, la Tableu Economique puede \\
& stock de capital (Hidalgo, 1998). & leerse en clave del desarrollo al considerar la \\
& Asimismo, para los mercantilistas a la acumulación & reproducción anual de la renta. Se consideraba \\
[Cont. pág. & no se podía llegar sin un papel predominante del Es- & que cada año la riqueza crecía por medio de los \\
sgte.] & tado, dado que según ellos al Estado le correspondía & excedentes agrarios comparándolos con el año \\
& regular las transacciones comerciales en lo & anterior, y esto ocurría a consecuencia de las \\
\cline { 2 - 3 }
\end{tabular}

(2) El fin de hablar de cada una de las corrientes económicas que se van a desarrollar en este escrito no es establecer todo el acervo teórico de cada una de las escuelas ya que estaría por encima de este trabajo, sino abrir la trazabilidad de la evolución de la categoría.

(3) Se utiliza el prefijo «pre» para dar a entender que antes de 1776 no había nacido la ciencia económica; históricamente se tiene referenciado que la economía nace con el libro del padre de la economía, Adam Smith. Al respecto, el profesor Naredo (2003:74) dice lo siguiente: «Si antes del siglo XVII no existía su acepción actual la palabra economía, tampoco se había instaurado la noción hoy usual de producción». 


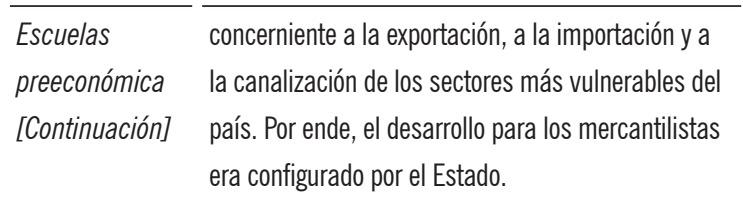

\begin{tabular}{ll}
\hline Economía & Adam Smith \\
Clásica & Hay varios teóricos que dicen que la primera persona \\
& que expresó coherentemente las teorías del desarrollo \\
& fue el padre de la economía, Adam Smith (Hagen, \\
& 1971), quien al configurar la metáfora de la «mano \\
& invisible» del mercado reflejó que cada uno de los \\
& agentes busca su interés egóísta, lo cual sumando las \\
& partes contribuye al bienestar general. Smith (1176) \\
& también abordó en su libro aspectos relacionados con \\
& la cooperación social, la justicia, la autoestima, la \\
& libertad para las colonias y la educación. Es por ello \\
& que Amartya Sen (1997) destacó estos aspectos para \\
& contraargumentar a los detractores de Smith como \\
& pionero en la teoría del desarrollo.
\end{tabular}

\section{Ricardo}

Según Hidalgo (1998:22) Ricardo fue uno de los

teóricos clásicos que construyó una de las mejores teorías del Desarrollo. Para Ricardo (1817) la base del desarrollo está en comunión con las rentas de la tierra, y para ser más específicos en la escasez de la tierra. De ahí se sigue que el beneficio estará en consonancia con las personas que explotan las mejores tierras en detrimento de las tierras menos fértiles. Desde el punto de vista de salarios, se puede afirmar que el desarrollo según Ricardo va en sintonía con los beneficios de acumulación que se orquestan con el crecimiento económico, y si estos beneficios son mínimos en el empleo el crecimiento se verá. Para finalizar, Ricardo afirma que si no hay desarrollo no habrá crecimiento y por ende se generará un estado estacionario en la economía. mejoras ocurridas en el área tecnológica (Naredo, 2003:99-115). Por tanto, para los fisiócratas el crecimiento de la agricultura era la causa y la consecuencia del desarrollo económico de un territorio, en este caso, el de Francia.

\section{Malthus}

La mayor propuesta que dejó Malthus (1798) para las teorías del desarrollo fue su libro Ensayo sobre el principio de la población. ${ }^{4}$ Allí, el autor explica el "principio de la población" donde infiere que la población crece geométricamente, mientras que los recursos lo hacen en progresión aritmética. Por ende, la reducción de la población deviene como un factor de desarrollo para un Estado.

\section{Marx}

Karl Marx fue unos de los grandes economistas del siglo XIX; disidente de los anteriores autores, proponía que el capitalismo no podría generar desarrollo. Sus propuestas desde el punto de vista de la teoría del desarrollo no toman como base el capitalismo sino una nueva corriente emergida en los desencantos producidos por el capitalismo nombrada socialismo. Para Marx el desarrollo humano es la base de la economía como una lucha de reivindicación de los derechos sociales.

El desarrollo para Marx se manifiesta en los conceptos de plusvalía, plus valor, ejército de reserva, valor de cambio, valor de uso, acumulación capitalista vs salario de miseria, eliminación de la propiedad privada, lucha de clases que surge dada las incoherencias de la acumulación de los agentes económicos, entre otros. Estos conceptos construyen el andamiaje de una nueva sociedad en la cual lo humano es más importante que la acumulación (Hagen, 1971; Marx, 1973).

(4) Publicado en el año 1798. 
Gómez Rodríguez y otros / El Biodesarrollo...

\begin{tabular}{|c|c|c|}
\hline Neoclásicos & Escuela Historicista & $\begin{array}{l}\text { List } \\
\text { El sistema nacional de economía política fue el } \\
\text { nombre que colocó List (1841) a su libro cumbre, } \\
\text { en el cual se observan teorías del desarrollo a tra- } \\
\text { vés de las etapas de desarrollo. Estas se pueden } \\
\text { dividir en cinco estadios. El primero denominado } \\
\text { "primitivo", que va de la mano con la esclavitud; } \\
\text { el segundo "pastoril", donde lo más importante es } \\
\text { la agricultura; tercero cuando surge la "industria- } \\
\text { lización"; el siguiente denominado estadío agrope- } \\
\text { cuario-manufacturero-comercial y la última etapa } \\
\text { designada agrícola-manufacturera-comercial. } \\
\text { Para List el desarrollo es un proceso lineal que va } \\
\text { por etapas (Hidalgo, 1998:35) y el análisis de la } \\
\text { economía no puede estar por fuera de la historia o } \\
\text { de la contextualización de los procesos producti- } \\
\text { vos con las dinámicas sociales. }\end{array}$ \\
\hline $\begin{array}{l}\text { Escuela } \\
\text { de Lausana } \\
\text { y Escuela } \\
\text { Austriaca }\end{array}$ & $\begin{array}{l}\text { Los grandes contribuyentes a la economía y a las } \\
\text { teorías del desarrollo desde estas escuelas fueron } \\
\text { Carl Menger, Leon Walras y Alfred Marschal entre } \\
\text { otros. Estos economistas modelaron la economía a } \\
\text { través de la instrumentalización de las matemáti- } \\
\text { cas y de supuestos básicos como la competencia } \\
\text { perfecta, teoría de la racionalidad. Su base con- } \\
\text { ceptual del desarrollo se centraba en la función de } \\
\text { producción y en que la remuneración de los factores } \\
\text { de producción tenía una posible productividad } \\
\text { marginal. De ahí, se concluye que si se aumenta } \\
\text { uno de estos factores, la productividad marginal se } \\
\text { acrecentará. Por ende, estos autores consideran al } \\
\text { desarrollo económico como un proceso continuo, } \\
\text { acumulativo, armónico y gradual (Hidalgo, 1998:45; } \\
\text { Martínez, 2001). } \\
\text { Desde otra perspectiva pero en el mismo orden de } \\
\text { ideas, la «economía Neoclásica y la del desarrollo } \\
\text { se diferencian en su visión sobre el funcionamiento } \\
\text { de los mercados. Para los Neoclásicos, los mer- } \\
\text { cados en los países en desarrollo funcionan; para } \\
\text { la economía del Desarrollo, los mercados en los } \\
\text { países pobres funcionan peor que los países ricos» } \\
\text { (Escribano, 2012:98). }\end{array}$ & \\
\hline
\end{tabular}




\begin{tabular}{|c|c|}
\hline $\begin{array}{l}\text { Pensamiento } \\
\text { Schumpeteriano }\end{array}$ & $\begin{array}{l}\text { Para Schumpeter no eran lo mismo desarrollo y } \\
\text { crecimiento económico, de donde se desprende } \\
\text { su separación del pensamiento Neoclásico. Para } \\
\text { este autor, el desarrollo es el cúmulo de cambios } \\
\text { fuertes que pretenden mover al sistema econó- } \\
\text { mico desde un punto de equilibrio a otro de nivel } \\
\text { superior, proviniendo de empresarios creativos e } \\
\text { innovadores. Por consiguiente, el desarrollo según } \\
\text { Shumpeter no es armónico ni lineal, sino disconti- } \\
\text { nuo y con cambios bruscos (Requeijo, 1983, citado } \\
\text { en Hidalgo, 1998:47; Schumpeter, 1967:1982). }\end{array}$ \\
\hline Keynesianismo & $\begin{array}{l}\text { Keynes, uno de los más grandes economistas del } \\
\text { siglo XX, contribuyó al acervo de las teorías del } \\
\text { crecimiento como a las del desarrollo económico } \\
\text { desde una nueva mirada dando preponderancia a la } \\
\text { política fiscal expansiva. } \\
\text { La preocupación para Keynes era el corto plazo, lo } \\
\text { cual quiere decir que no le dio tanta importancia al } \\
\text { desarrollo económico. No obstante, explicaba que } \\
\text { cuando un país llegaba a un nivel de ingresos muy } \\
\text { altos, dejaría de preocuparse por el crecimiento } \\
\text { económico estructurando el aumento en sus ingre- } \\
\text { sos hacia acrecentamiento del ocio, los servicios } \\
\text { sociales, las ocupaciones artísticas más civilizadas, } \\
\text { entre otros. (Singer, 1981; Keynes, 1976). }\end{array}$ \\
\hline $\begin{array}{l}\text { Perspectiva } \\
\text { de la } \\
\text { Modernización }\end{array}$ & $\begin{array}{l}\text { Entre } 1945 \text { y } 1980 \text { se pueden reconocer dos } \\
\text { vertientes de enfoques de las teorías del desarrollo, } \\
\text { entre ellas una denominada Modernización. Los re- } \\
\text { presentantes más emblemáticos de esta propuesta } \\
\text { fueron los economistas Lewis, 1958; Nurske, 1960; } \\
\text { y Baran, 1957, quienes consideraban que la base } \\
\text { del desarrollo era la acumulación de capitales y } \\
\text { que esto se lograba por la modernización del sector } \\
\text { industrial; es decir, con la ampliación incesante del } \\
\text { producto bruto industrial. Otro de los exponentes } \\
\text { de esta corriente fue Rostow, 1962, quien propuso } \\
\text { una especie de pirámide del crecimiento económico } \\
\text { y del desarrollo económico a través de diversas } \\
\text { etapas que deberían seguir los países para llegar } \\
\text { a ser modernos (sociedad tradicional, condiciones } \\
\text { previas al impulso inicial, despegue, y marcha hacia } \\
\text { la madurez) (Varcárcel, 2006:7-8). }\end{array}$ \\
\hline
\end{tabular}




\begin{tabular}{|c|c|}
\hline $\begin{array}{l}\text { Perspectiva de } \\
\text { la Dependencia }\end{array}$ & $\begin{array}{l}\text { Entre } 1965 \text { y } 1980 \text { aproximadamente nació una } \\
\text { segunda vertiente enfocada en América latina que } \\
\text { intelectualmente fue una contraposición con la } \\
\text { teoría de la Modernización. Su propuesta metodo- } \\
\text { lógica se basaba en interpretar dialécticamente } \\
\text { la realidad así como en analizar concretamente } \\
\text { y no generalizada los fenómenos económicos de } \\
\text { los países latinoamericanos. De ella subyacen dos } \\
\text { corrientes: una afirmaba que el desarrollo era el } \\
\text { resultado del imperialismo político-económico } \\
\text { desde una base conceptual de Rosa de Luxembur- } \\
\text { go y de Lenin. Y la otra que se podría definir como } \\
\text { estructuralista, era liderada por el economista } \\
\text { Prebisch quien junto a otros intelectuales de la } \\
\text { región instauró la CEPAL y afirmaba que el creci- } \\
\text { miento económico de América latina debía lograrse } \\
\text { "hacia adentro". }\end{array}$ \\
\hline $\begin{array}{l}\text { Perspectiva del } \\
\text { Desarrollo a } \\
\text { Escala Humana }\end{array}$ & $\begin{array}{l}\text { El mayor representante de esta corriente es } \\
\text { Manfred Max Neef. En su libro Desarrollo a escala } \\
\text { humana; una nueva opción para el futuro propone } \\
\text { desprenderse de la modernización homogenizante, } \\
\text { discutir, pensar en los valores de uso, y sobre } \\
\text { todo dimensionar la diversidad del ser humano } \\
\text { desigualando las satisfacciones y las necesidades } \\
\text { de los seres humanos (Varcárcel, 2006:19). }\end{array}$ \\
\hline $\begin{array}{l}\text { Desarrollo } \\
\text { humano vs. } \\
\text { capital humano }\end{array}$ & $\begin{array}{l}\text { Según el PNUD «El desarrollo humano es mucho } \\
\text { más que el crecimiento o caída de los ingresos } \\
\text { de una nación. Busca garantizar el ambiente } \\
\text { necesario para que las personas y los grupos } \\
\text { humanos puedan desarrollar sus potencialidades y } \\
\text { así llevar una vida creativa y productiva conforme } \\
\text { con sus necesidades e intereses. Esta forma de } \\
\text { ver el desarrollo se centra en ampliar las opciones } \\
\text { que tienen las personas para llevar la vida que va- } \\
\text { loran, es decir, en aumentar el conjunto de cosas } \\
\text { que las personas pueden ser y hacer en sus vidas. } \\
\text { Así el desarrollo es mucho más que el crecimiento } \\
\text { económico, este es solo un medio —uno de los } \\
\text { más importantes_- para expandir las opciones de } \\
\text { la gente» (2012:56). }\end{array}$ \\
\hline $\begin{array}{l}\text { [Cont. pág. } \\
\text { sgte.] }\end{array}$ & $\begin{array}{l}\text { El concepto de desarrollo humano se construyó en } \\
\text { la década de } 1990 \text { del siglo pasado al tratar }\end{array}$ \\
\hline
\end{tabular}




\begin{tabular}{|c|c|}
\hline \multirow{37}{*}{$\begin{array}{l}\text { Desarrollo } \\
\text { humano vs } \\
\text { capital hun } \\
\text { [Continuac }\end{array}$} & de concebir las diferentes características del ser \\
\hline & humano desde el derrotero en que el individuo está \\
\hline & en el centro del desarrollo, y trata de potencializar \\
\hline & como promocionar las posibilidades de disfrute de \\
\hline & la «libertad» (Moleiro et ál., 2007; PNUD, 1990). \\
\hline & El concepto tiene sus inicios, como lo explica Sen \\
\hline & (2000) (1995) y (1998) en las ideas del filósofo \\
\hline & ateniense Aristóteles (2008) quien indicaba que \\
\hline & al ampliar todas las capacidades del ser humano \\
\hline & se concebía el fin del desarrollo humano. En \\
\hline & el mismo sentido Amartya Sen explica que «el \\
\hline & desarrollo puede concebirse (...) como un proceso \\
\hline & de expansión de las libertades reales de las que \\
\hline & disfrutan los individuos» (Sen, 2000:19). Es decir, \\
\hline & que el desarrollo humano es la ampliación de las \\
\hline & libertades de los sujetos. \\
\hline & Amartya Sen identifica lo preponderante del \\
\hline & crecimiento económico como variable para ampliar \\
\hline & las «libertades», pero siguiendo a Aristóteles la \\
\hline & riqueza no puede ser un fin en sí mismo. En con- \\
\hline & secuencia, lo interesante de la riqueza, si se puede \\
\hline & utilizar este adjetivo, son las facultades que el \\
\hline & individuo puede lograr con ella. En lo concerniente \\
\hline & al Capital Humano este es diferente del Desarrollo \\
\hline & Humano, dado que el primero tiende a centrar su \\
\hline & mirada hacia la capacidad de las individuos de \\
\hline & aumentar la producción, mientras que el segundo \\
\hline & es la capacidad de «libertad de los sujetos para \\
\hline & vivir en la forma que tengan valorada dentro de \\
\hline & una canastas de capacidades que puedan elegir \\
\hline & (Edo, 2002:19-30). Para terminar, Amartya Sen \\
\hline & escribió: «Debemos ir más allá del concepto \\
\hline & del Capital Humano una vez reconocidos su \\
\hline & importancia y su alcance. La ampliación necesaria \\
\hline & es adicional e inclusiva y en modo alguno una \\
\hline & alternativa a la perspectiva del capital humano» \\
\hline & (Sen, 2000:354). \\
\hline \multirow{4}{*}{$\begin{array}{l}\text { Perspectiva del } \\
\text { posdesarrollo }\end{array}$} & Uno de los grandes representantes de esta \\
\hline & corriente es el profesor Escobar (2014) quien en \\
\hline & sus estudios trata de dimensionar el desarrollo a \\
\hline & través de la diversidad de los grupos, la autonomía \\
\hline [Cont. pág. & de los mismos y de la no linealidad del desarrollo, \\
\hline sgte.] & sino más bien que cada grupo o persona encuentre \\
\hline
\end{tabular}




\begin{tabular}{|c|c|c|}
\hline $\begin{array}{l}\text { Perspectiva del } \\
\text { posdesarrollo } \\
\text { [Continuación] }\end{array}$ & $\begin{array}{l}\text { sus formas de entender, comprender y mantener } \\
\text { sus relaciones subjetivas, intersubjetivas, sim- } \\
\text { bólicas con su entorno en una relación simbiótica } \\
\text { como el centro de su existencia. }\end{array}$ & \\
\hline Perspectivas & $\begin{array}{l}\text { Desarrollo local, Desarrollo endógeno, Desarrollo } \\
\text { territorial, Desarrollo Regional. }\end{array}$ & $\begin{array}{l}\text { Entre sus principales autores están Sergio Boisier } \\
\text { que establece que "el desarrollo regional consiste } \\
\text { en un proceso de cambio estructural localizado en } \\
\text { un ámbito del territorio dominando región (Boisier, } \\
\text { 2001:6); así como "la diferencia entre local y lo } \\
\text { regional es la escala en que se mide" (Boisier, } \\
\text { 2001:11). En el mismo sentido, Antonio Vásquez } \\
\text { Baquero, que afirma que la "teoría del desarrollo } \\
\text { endógeno reconoce, por lo tanto, la existencia } \\
\text { de rendimientos crecientes de los factores } \\
\text { acumulables y el papel de os actores económicos, } \\
\text { privados y públicos en la decisiones de inversión y } \\
\text { localización" (Vázquez, 2000:5) }\end{array}$ \\
\hline
\end{tabular}

\section{Biodesarrollo}

La comprensión del biodesarrollo exige una clarificación acerca del concepto de bios. Es imposible hacer economía hoy en día sin tener una idea básica de qué es la vida (Diéguez, 2008). El reconocimiento de lo que sea la vida pasa, medularmente, por la importancia de la interculturalidad y el diálogo de civilizaciones. De esta manera el fundamento de la vida es la diversidad, la biodiversidad, la cual consiste en diversidad cultural, diversidad biológica y diversidad genética.

Por consiguiente, el biodesarrollo reconoce que no existen diferencias de naturaleza sino diferencias cualitativas, de grado 0 de organización entre la vida y la no vida. El biodesarrollo es una propuesta propositiva y proactiva hacia la afirmación, la gratificación, la exaltación y la posibilidad de la vida misma, tanto de la vida humana como de la vida en general sobre el planeta. De igual forma, el concepto de biodesarrollo se entiende como llamado y puesta en marcha de la redistribución de responsabilidades basado en la variedad de tareas e intereses dirigidos hacia la seguridad humana y la soberanía alimentaria.
En el mismo sentido, el biodesarrollo también se entiende como rechazo y transformación del control y el autoritarismo a favor de procesos de cooperación e integración en términos de procesos abiertos y continuados de aprendizaje, aprendizaje recíproco y horizontal, apertura a nuevas alternativas, métodos estándares y modos de vida con base en la mejor ciencia de punta. A su vez, el biodesarrollo constituye un desplazamiento de los tradicionales indicadores económicos a través de mediciones de bienestar y calidad de vida, felicidad, gestión del conocimiento, innovación, integración con la naturaleza y armonía y belleza.

De igual manera (Maldonado, 2014) enfatiza que el biodesarrollo deja de ser antrópico y sitúa, por primera vez, de manera directa, a la vida en general sobre el planeta como el pivote de toda la humanidad, alejándose así de lo expresado por la corriente neoclásica de la economía que sólo reconoce un papel antropocentrista del modelo, pues se trata de encontrar un desarrollo para y en función de la vida, de los sistemas vivos, y no únicamente de los seres humanos (Gómez, 2016). 
Profundizando en el concepto de biodesarrollo, el autor argumenta que es desarrollo en términos de los tiempos de la naturaleza y así corresponde exactamente a una naturalización de los temas relativos a: producción, consumo, formas y estándares de vida, llegando a plantear las siguientes ideas centrales de la Bioeconomía y el biodesarrollo: 1. Reducir el consumo: debemos poder evitar las mercancías inútiles; 2. Saber qué se quiere. Qué necesitamos; 3. Prohibición del armamento de guerra. Asimismo aclara que el patrón social del biodesarrollo es la autoorganización entendida como la devolución del control a los niveles operativos de las unidades básicas de la organización social en las que el liderazgo emerge. La autoriganización se nutre de los procesos y dinámicas del conocimiento que, a su vez, es un bien libre para todos y cada uno (Carpintero, 2006; Gómez, Rincón e lbagon, 2015).

Por consiguiente, el aspecto más sensible del desarrollo en general es el tema de la equidad; se encuentra así otro punto de acuerdo mutuo con la economía ecológica y se aleja aún más de la corriente neoclásica. El biodesarrollo es el camino a seguir, según el autor, para la construcción y el fortalecimiento de la equidad y como transformación radical del egoísmo y el individualismo hacia una amplia y sólida conciencia social, planetaria y ecológica. De igual forma, el biodesarrollo se erige como un proceso de confianza en la autonomía local sobre la base del reconocimiento explícito de los límites de la naturaleza y del papel central de la entropía (Useche, 2011).

Por lo tanto, Maldonado (2014) realiza un análisis de lo que significa el biodesarrollo como alternativa teórica actual al devenir económico de la sociedad. Establece que la bioeconomía o economía ecológica ha llegado a ser considerada como la economía ecológica proponiendo como nuevos temas junto con el biodesarrollo como evolución natural del concepto — la calidad de vida, la dignidad en la vida, la conservación, la preservación, la sostenibilidad y el tiempo. Maldonado establece que la fuente última de riqueza es la naturaleza y el sistema capitalista atentó de manera sistemática y radical contra ella; por ello, sin dificultad, cualquier confrontación con la naturaleza la lleva perdida el ser humano con toda seguridad.

Junto con la crítica a la economía neoclásica hecha por Paul Krugman, se argumenta que es cierto que a partir de la crisis medioambiental y el énfasis en la importancia del crecimiento económico y la explotación 0 aprovechamiento de los recursos naturales, que la economía se encuentra en una profunda crisis epistemológica, pues una sociedad, una cultura 0 una civilización no puede agredir a la fuente de la riqueza impunemente ya que en el orden natural la acción humana se vuelve contra sí misma. Está tan verdaderamente enfermo el modelo inoperante de desarrollo de 0ccidente que sitúa al ser humano por encima y por fuera de la naturaleza, y a ésta como objeto de explotación para beneficio del ser humano. El desarrollo ha estado esencialmente vinculado y sujeto a relaciones de dependencia del crecimiento económico.

El autor sugiere que el futuro de la economía ya está aquí y se llama Bioeconomía.

Maldonado (2014) propone que el estudio futuro de las ciencias económicas se encuentra del lado de las ciencias de la complejidad; así, el biodesarrollo, como pilar fundamental de este futuro nombrado, es el núcleo de la Bioeconomía y ésta es, precisamente, el antecedente de aquélla. Dentro de las preocupaciones del biodesarrollo se encuentra el reconocimiento a la importancia de la segunda ley de la termodinámica ya que ayuda a poner de manifiesto las sin-salidas de la economía en relación con la idea de entropía. En palabras del autor, «el biodesarrollo es desarrollo, cuidado y posibilidad de la vida, y no ya simple y llanamente de la economía y del aparato productivo» (78).

\section{Conclusiones}

La Bioeconomía y el biodesarrollo son economía y desarrollo de cara a la naturaleza y en función de la vida contrario a los modelos económicos vigentes de 
libre mercado que basan sus conceptos en ideales de crecimiento. El biodesarrollo puede y debe ser entendido en el sentido de una forma de vida en términos de armonía para dirigir la mirada hacia la estética y no la acumulación.

Por otra parte, la categoría desarrollo ha estado en todas las escuelas económicas, desde las que la observan bajo la férula de la eficiencia y la eficacia, hasta las que tratan de dimensionarla más allá de estas premisas configurándola por medio de relaciones intersubjetivas con los actores sociales en su entorno inmediato. No obstante, en el presente el
Biodesarrollo trata de dimensionar la relación entre el ser humano con sus subjetividades como sus representaciones simbólicas; sin olvidar que han tratado también de superar la visión antropocentrista por una mirada más Biocentrista. En consecuencia, las teorías del desarrollo en la ciencia económica siguen todavía en sustentación dado que es tan rica que definirla como reducirla sería finiquitar el discurso el cual tiene mucho por decir, en virtud de os cambios vertiginosos del ecosistemas como de la misma ciencia económica.

\section{Referencias bibliográficas}

- Agencia Europea de Medio ambiente (AEMA). (2015, marzo). El medio ambiente en Europa en 2015: el bienestar futuro depende de medidas más audaces en materia de política, conocimiento, inversión e innovación. Recuperado en marzo de 2012 de Agencia Europea de Medio ambiente: http://www.eea. europa.eu/es/pressroom/newsreleases/el-medio-ambiente-en-europa

- Andrade, L.E. (1994-1996). Analogías entre las teorías sobre la materia, la evolución biológica y la sociedad. Memorias del Seminario de Ciencias Teóricas, conferencias 1994-1996. Colección Memorias, 8, 1-32. Recuperado de https://www. academia.edu/2630885/ANALOGIAS MATERIA_-EVOLUCION_SOCIEDAD_ ACCEFN_Colecci\%C3\%B3n_Memorias_No_8_1996? auto = download

- Aristoteles. (2008). Ética Nicomaquea. Buenos aires: Editorial Porrua. - Banco Interamericano de Desarrollo (BID). (2012). Bajemos la temperatura. Porque se debe evitar un planeta 4 grados más cálido. Recuperado en marzo de 2012 de: http:// wwwwds.worldbank.org/external/ default/WDSContentServer/WDSP/IB /2013/06/13/000445729 2013061 3121114/Rendered/PDF/632190v20 SPANI00heatOreportOSpanish.pdf

- Baran, P. (1957). The political economy of growth. New York: Monthly Reviews Press.

- Boisier, S. (2001). Sociedad del conocimiento, conocimiento social y gestión territorial. Estudios Sociales, 107(1), 95-139.

- Cardoso, F., y Faletto, E. (1971). Dependencia y desarrollo en América Latina. México: Siglo XXI.

- Carpintero, 0. (2006). La Bioeconomía de Goergescu-Roegen. España: Montesinos ensayo.

- Diéguez, A. (2008, noviembre). ¿Es la vida un género natural? Dificultades para la definición del concepto vida. Artefactos, 1(1), 81-100. - De Soussa Santos, B. (2011). Una epistemología del sur. Buenos Aires: Clacso Ediciones.

- De Rivero, 0. (1998). El mito del desarrollo. Los países inviables en el siglo XXI. Lima: Mosca azul.
- Do Santos, T. (1969). Socialismo y Fasicsmo. Lima:UNSMS.

- Edo, M. (2002). Amartya Sen y el desarrollo como libertad. La viabilidad de una alternativa a las estrategias de promoción del desarrollo. Buenos Aires: Universidad Torcuato diTella. Departamento de Ciencia Política y Gobierno. Licenciatura en EstudiosInternacionales. Recuperado de http://www.colombiaaprende. edu.co/html/docentes/1596/articles-346050 recurso 3.pdf

- Escobar, A. (2014). Más allá del Desarrollo: Posdesarrollo y transiciones hacia el pluriverso. En J. Losada y J. Barrea, Lecturas criticas del desarrollo. Perspectivas Latinoamericanas (pp. 25-70). Bogotá: Editorial Bonaventuriana.

- Escribano, G. (2012). Teorías del desarrollo económico. Recuperado el 29 de marzo de 2012 de:

-http://www.scribd.com/ doc/58320946/Teorias-DesarrolloEconomico-Social-pdf-Usac-cunoc - Frank, G. (1973). Subdesarrollo o revolución. México: ERA. 
- Goergescu-Roegen, N. (1996). La ley de la Entropía y el proceso económico. Madrid: Fundación Argentaria.

- Gómez, D. (2016) La Bioeconomía como integración: Innovación frente al Cambio Climático. Ponencia presentada en el Webinario de la Red Latinoamericana de Investigadores sobre Integración Red LISI. AUALCPI, 04 de mayo 2016.

-_ (2013a). La vida y la Bioeconomía. Breve análisis desde algunas corrientes de las Ciencias Naturales, de la Economía y la Filosofía. IGNIS, 7, 8-14.

- _- (2013b). El lenguaje y el accionar nocivo de la economía clásica bajo el pseudónimo del neoliberalismo en la vida. Silogismo, (1), 80-83.

- Gómez., D., Rincón, M., y lbagon, J. (2015). Breve análisis de la Carta Encíclica Laudato Si' del Santo Padre Francisco sobre el Cuidado de la Casa Común desde la Bioeconomía y Biodesarrollo. Revista Criterios, 8(2), 133-15.

- González, P. (1970) Sociología del desarrollo latinoamericano. México: UNAM.

- Hagen, E. (1971). La teoría económica del desarrollo. Buenos Aires: Amorrortu.

- Hidalgo, L. (1998). El pensamiento econòmico sobre desarrollo. De los mercantilistas al PNUD. Recuperado de Universidad de Huelva:

- http://www.uhu.es/antonio.hidalgo/documentos/pesd.pdf

- Hinkelammert, F., y Mora, H. (2008). Hacia una economía para la vida. Preludio para una reconstrucción de la economía. San José de Costa Rica: Editorial tecnológica de Costa Rica.
- Keynes, J. (1976). Teoría general de la ocupación, el interes y le dinero. México: Fondo de Cultura Económica.

- List, F. [1841 (1955)]. El sistema nacional de economía política. Madrid, España: Aguilar.

- Lewis, A. (1958). Teoría del desarrollo económico. México: FCE.

- Maldonado, C. (2014). Biodesarrollo y complejidad. Propuesta de un modelo teórico. En M. Eschenhaguen, Alternativas al desarrollo (pp 71-95). Bogotá: UR-PUB.

- Martínez, C. (2001). Breve historia del pensamiento económico. Recuperado de: http://www.eumed. net/cursecon/1c/pensamiento-economico.htm.

- Maturana, H., y Pörksen, B. (2004). Del Ser al hacer. Lor orígenes de la biología del Conocer. Barcelona: J.C.Saenz editor.

- Maturana, H. (2002). El sentido de lo Humano. Madrid: Océano.

- Malthus, T. [1798 (1986)]. Ensayo sobre el principio de población. México: Fondo de Cultura Económica.

- Marx, K. (1973). El capital. México: Fondo de Cultura Económica.

- Max-Neef, M. (1995). Economic growth and quality of life: athreshold hypothesis. Ecologica Economics, 15, 115-118.

- Moleiro, 0., Otero, I., y Nieves, Z. (2007). Aprendizaje y desarrollo humano. Revista Iberoamericana de educación, 44(3), 1-9. Recuperado de file:///C:/Users/CIDAE\%20-\%20 08/Downloads/1901Perez.pdf

- Muñoz, D. (2016). La cuestión animal: un desafío para el humanismo iEl fin del hombre? Humanismo y anti humanismo en la filosofía contemporánea. Colombia: Universidad San Buenaventura.
- Naredo, J. (2003). La econompía en evolución. Historia y perspectiva de las categorías básicas del pensamiento de la economía. Barcelona: Siglo XXI.

- Nurske, R. (1960). Problemas de formación de capitales en países insuficientemente desarroIlados. México: Fondo de Cultura Económica.

- PNUD (1990) Informes sobre el Desarrollo Humano. Bogotá, Colombia: Tercer mundo editores. Recuperado de http://hdr.undp.org/sites/ default/files/hdr_1990_es_completo nostats.pdf

-__ (2012). Programa de las Naciones Unidas para el Desarrollo. Recuperado en mayo 2016 de:

- http://www.pnud.org.co/sitio.shtml?apc $=$ aAa020081-$\mathrm{ym}=$ aye $=\mathrm{A}$

- Prebisch, R. (1967). Hacia una dinámica del desarrollo latinoamericano. Uruguay: Orientaliciones de la banda.

- Requeijo, J. (1983). Tres visiones del capitalismo. Papeles de economía española, 17, 2-22.

- Ricardo, D. (1817). On the Principles of Political Economy and Taxation. London: Jhon Murray.

- Rostow, W. (1962). The stage of economic growth. A non Communist manifest. New York: Cambridge University Press.

- Salcedo Casallas, J. (2016, septiembre). El docente universitario y el Sistema de comunicación de gubernamentalidad neoliberal. Hojas y Hablas, 12, 20-40. Recuperado de http://virtual. fum.edu.co/publicaciones/index.php/ hojasyhablas/article/view/2

- Schumpeter, P. (1967). Teoría del desarrollo económico. México: Fondo de Cultura Económica. 
Sen, A. (1995). ilgualdad de qué? En S. Mc Murrin (Ed.), Ciclo Tanner de Conferencias sobre los Valores Humanos. Universidad de Stanford: Cambridge University Press.

- — (1997). Development thinking at the beguinning of the XX century. Economic and social development XX century. Washington: Inter-American Developmnet bank/ Johns Hopkings University Press.

- _ (1998). Teorías del desarrollo a principios del Siglo XXI. En L. Emmerij y J. Núñez (comps.), El desarrollo económico y social en los umbrales del siglo XXI. Washington: Banco Interamericano de Desarrollo. Recuperado de http://www.revistas. unal.edu.co/index.php/ceconomia/ article/viewFile/11497/20792
- —(2000). Desarrollo como Libertad. Madrid: Editorial Planeta.

- Singer, H. (1981). Los modelos Keynesianos del desarrollo económico sobre los países subdesarrollados. Un análisis a partir de la obra de Gunnar Myrdal Asian Drma. En H. Singer, Estrategia del desarrollo internacional. Ensayos sobre el atraso económico (pp. 45-66). México, Fondo de Cultura Económica.

- Smith, A. [1776 (2001]. La riqueza de las naciones. España: Editorial Alianza.

- Stiglitz, J. (2010). Caída libre. El libre mercado y el hundimiento de la economía mundial. México: Taurus.

- Sunkel, 0. (1995). El desarrollo desde adentro. México: FCE.

- Useche, 0. (2012). Reestructuración "bio-económica" del capita- lismo y su impacto en la reconfiguración del Estado y la ciudadanía. En R.G. Meyer y Howards Richards (comps.), Hacia otras economías. Críticas al paradigma dominante (pp. 231-266). Bogotá: Uniminuto. - - (2011). Biodesarrollo y economía campesina. Bogotá: Uniminuto.

- - (2008). Los nuevos sentidos del desarrollo. Ciudadanías emergentes, paz y reconstrucción. Bogotá: Universidad Minuto de Dios. - Varcárcel, M. (2006). Génesis y evolución del concepto y enfoque sobre el desarrollo. Lima: Pontificia Universidad Católica del Perú.

- Vázquez, A. (2000). Desarrollo endógeno y Globalización. Revista Eure, 26(79), 47-65.
Registro bibliográfico

Gómez Rodríguez, D.T., Barbosa Pérez, E.M., y Rojas Velásquez, W.E. (2016). El Biodesarrollo como ruptura de la categoría desarrollo. Revista Ciencias Económicas, 13(02), 75-87. 